\title{
Lead and Cadmium Exposure Assessment Using Biomarkers Collected from Children Living in an Industrial Complex Area in Korea
}

\author{
Jina Heo and Jong-Tae Lee* \\ Department of Environmental Health, College of Health Science, Korea University, San 1 Jeongneung-dong, Seongbuk-gu, \\ Seoul 136-703, Korea \\ *Corresponding author. Tel: +82-2-940-2867, Fax: +82-2-940-2867, E-mail: jtlee@korea.ac.kr
}

\begin{abstract}
Children are particularly vulnerable to adverse health effects associated with heavy metal exposure. The goal of this study was to investigate the relationship between proximity to an industry complex and blood lead and urinary cadmium levels for children aged 7-13 who lived in Ulsan where a big petrochemical complex is located. We conducted a questionnaire survey to collect data including sociodemographics, daily habits, residential environment, etc. We also analyzed blood lead and urinary cadmium levels using Atomic Absorption Spectrometry (AAS). Data were analyzed using regression analysis. All statistical analyses were conducted with SAS software version 9.2. We calculated distance by using a Geographic Information System (ArcGIS version 10.0). The geometric mean blood lead level was $1.55 \mu \mathrm{g} / \mathrm{dL}$ (boys: $1.59 \mu \mathrm{g} / \mathrm{dL}$, girls: $1.51 \mu \mathrm{g} / \mathrm{dL}$ ), and the geometric mean urinary cadmium level was $0.51 \mu \mathrm{g} / \mathrm{g}$ creatinine (boys: $0.45 \mu \mathrm{g} / \mathrm{g}$ creatinine, girls: $0.58 \mu \mathrm{g} / \mathrm{g}$ creatinine). In the results of regression analyses, we found that urinary cadmium levels significantly decreased as distance between residence and industrial complex increased after adjusting for age, gender, income, passive smoking and the length of residence. This result was opposite to that for lead levels. Our observations support the hypothesis that urinary cadmium levels in children are related to their proximity to an industrial complex.
\end{abstract}

Key words: Blood lead, Urinary cadmium, Children, Korea, Heavy metal

\section{INTRODUCTION}

Human exposure assessments using biomarkers have been conducted in many countries. The NHEXAS (National Human Exposure Assessment Survey) has been running since 1995 in the United States and the GerES (German Environmental Survey) has been conducted since 1985 in Germany. In Korea, the "Korean National Human Exposure and Bio-monitoring Examination" has been conducted to investigate concentrations of harmful chemical substances including heavy metals and identify risk factors. Based on the results of this assessment, a survey entitled "A Prospective Cohort Study of Environmental Pollutants: A study in an industrial complex area" was performed targeting an industrial area where residents are more likely to be exposed to harmful substances.

Lead and cadmium represent heavy metals which have deleterious effects on the human body and are available from various sources. The main sources of general lead exposure are gasoline, industrial emissions, and lead paint. Lead exposure through inhalation and ingestion is increased near lead-emitting industries (Zheng et al., 2008; Levallois et al., 1991). Toxic effects may occur in the central and peripheral nervous systems, blood, kidneys, cardiovascular, endocrine, immune systems, gastrointestinal tract, and male reproductive organs (Nordberg, 2007). Cadmium is used in electroplating and galvanizing, as a cathode material for nickel-cadmium batteries, and as a color pigment in paints and plastics. In the general population the major source of cadmium is food (Klaassen and Watkins, 2003). Cadmium is also absorbed by inhaling air which is polluted by environmental tobacco smoke, house dust, and industrial emissions. It is more effectively absorbed in the airways (up to 66\%) than in the gastrointestinal tract (3-7\%) (Schoeters et al., 2006). It is excreted very slowly from the human body and accumulates mainly in the kidneys. The principal longterm effects of low-level exposure to cadmium are chronic obstructive pulmonary disease, emphysema, and chronic renal tubular disease (Klaassen and Wat- 
kins, 2003).

In Korea, lead levels in the air had been decreasing on an annual basis and in recent years have maintained a constant level (National Istitute of Environmental Research, 2010). In 2009, lead levels of major cities were $0.0296-0.0697 \mu \mathrm{g} / \mathrm{m}^{3}$ and there were no cases that exceeded Korean annual standard of $0.5 \mu \mathrm{g} / \mathrm{m}^{3}$. Cadmium levels were $0.0007-0.0028 \mu \mathrm{g} / \mathrm{m}^{3}$ in 2009 which are below the World Health Organization (WHO) guideline of $0.005 \mu \mathrm{g} / \mathrm{m}^{3} /$ year (National Istitute of Environmental Research, 2010). According to the "Korean National Human Exposure and Bio-monitoring Examination", the geometric mean of blood lead levels for adults was $1.98 \mu \mathrm{g} / \mathrm{dL}$ (male: $2.55 \mu \mathrm{g} / \mathrm{dL}$, female: $1.77 \mu \mathrm{g} / \mathrm{dL}$ ) and that of the urinary cadmium was $0.76 \mu \mathrm{g} / \mathrm{g}$ creatinine (male: $0.60 \mu \mathrm{g} / \mathrm{g}$ creatinine, female: $0.84 \mu \mathrm{g} / \mathrm{g}$ creatinine) (National Institute of Environmental Research, 2008).

A more effective way of resolving problems associated with heavy metals would be to reduce the exposure level rather than to provide treatment after health effects have occurred. There are data demonstrating that children develop signs and symptoms at low bloodlead concentrations and have higher absorption of lead than adults. Also, the urinary excretion of cadmium peaks in the age range of 6-12 years. This peak is explained by the increased intake per person in this particular age range and the growth rate of the kidney, leading to a peak in kidney cadmium concentration. The calorie intake per person increases rapidly during the period of 6-20 years-of-age; therefore, it follows that the daily intake of metal also increases during this time. As such, management of sources is needed in areas where children have an increased opportunity for exposure (Nordberg, 2007).

In epidemiology, exposure assessment is the classification of attributes of subjects or environmental agents relevant to their health, with the assignment of numerals or other signs to these classes according to predetermined rules. The variable of real interest, the true exposure, may not be directly measurable or it may be difficult or impossible to define (Armstrong et al., 1992). People spend much time in residence and live around the residence (Brasche et al., 2005; Jenkins et al., 1992). So we assumed that the location of residence is related to his level of exposure. It is clearly not a cause of disease but an indicator of level or probability of exposure to some true cause which may be unmeasured or unknown (Armstrong et al., 1992).

The goal of this study was to investigate the relationship between proximity to an industry complex and blood lead and urinary cadmium levels for children aged 7-13 who lived in Ulsan where a big petrochemical complex is located.

\section{METHODS AND MATERIALS}

\section{1 Study Population}

The study entitled "A Prospective Cohort Study of Environmental Pollutants: A study in an industrial complex area (Ulsan)" had been performed since 2003. Institutional Review Board (IRB) approval was obtained for the study. All participants were recruited via phone or information from contacted schools. We chose subjects participated in 2010, 7-13 years-of-age for our study $(\mathrm{N}=434)$. We limited study subjects to 434 participants who had exact address information and both blood lead levels and urinary cadmium levels available.

\section{2 Questionnaire Survey and Sampling}

Informed consent was obtained from each participant. A questionnaire was used to gather individual information on socio-demographic factors, daily habits, disease and drug history, residential environment, outdoor environment, etc. The questionnaire was sent to subjects beforehand so they could fill it out and bring it with them when they came for a physical examination, or for those who could not get the questionnaire in advance they received and answered it at the time of the exam. Following the physical examination, blood $(20 \mathrm{~mL})$ and urine $(50-100 \mathrm{~mL})$ samples were collected.

\section{3 Laboratory Methods}

Lead and cadmium concentrations were analyzed at the Seoul Clinical Laboratory using Atomic Absorption Spectrometry (AAS). Internal quality controls were assessed in every series of samples to check the reproducibility and accuracy of the measurements. In addition, the laboratory took part in external quality assessments organized by the National Institute of Environmental Research in Korea. The main parameters used for lead and cadmium determination were wavelengths of $238.3 \mathrm{~nm}$ and $228.8 \mathrm{~nm}$, respectively. The limits of detection were $0.02 \mu \mathrm{g} / \mathrm{dL}$ for lead in blood and $0.01 \mu \mathrm{g} / \mathrm{L}$ for cadmium in urine.

\section{4 Statistical Analyses}

Independent sample t-tests or analysis of variance (ANOVA) were used to determine the differences between the groups classified by gender, area, age, income, passive smoking and the length of residence. Simple and multiple regression analyses were carried out including gender, age, income, passive smoking and the length of residence. The models took the form:

$$
\begin{aligned}
\mathrm{Y}_{\mathrm{i}}= & \beta_{0}+\beta_{1}(\text { distance })+\beta_{2}(\text { gender })+\beta_{3}(\text { age }) \\
& +\beta_{4}(\text { income })+\beta_{5}(\text { passive smoking }) \\
& \left.+\beta_{6} \text { (the length of residence }\right)
\end{aligned}
$$


Table 1. Summary statistics of the study population and associations with lead $(\mathrm{Pb})$ and cadmium $(\mathrm{Cd})$ levels.

\begin{tabular}{|c|c|c|c|c|c|}
\hline & \multirow{2}{*}{$\mathrm{N}$} & \multicolumn{2}{|c|}{$\mathrm{Pb}(\mu \mathrm{g} / \mathrm{dL})$} & \multicolumn{2}{|c|}{$\mathrm{Cd}(\mu \mathrm{g} / \mathrm{g}$ creatinine $)$} \\
\hline & & $\mathrm{GM} \pm \mathrm{GSD}$ & p-value & $\mathrm{GM} \pm \mathrm{GSD}$ & p-value \\
\hline Total & 434 & $1.55 \pm 0.15$ & & $0.51 \pm 0.05$ & \\
\hline \multicolumn{6}{|l|}{ Gender } \\
\hline Girls & 228 & $1.51 \pm 0.14$ & & $0.58 \pm 0.07$ & \\
\hline Boys & 206 & $1.59 \pm 0.16$ & 0.45 & $0.45 \pm 0.04$ & 0.00 \\
\hline \multicolumn{6}{|l|}{ Age (years) } \\
\hline $7-10$ & 31 & $1.63 \pm 0.12$ & & $0.59 \pm 0.04$ & \\
\hline 11 & 149 & $1.14 \pm 0.23$ & & $0.66 \pm 0.05$ & \\
\hline 12 & 254 & $1.84 \pm 0.09$ & $<0.00$ & $0.43 \pm 0.04$ & $<0.00$ \\
\hline \multicolumn{6}{|l|}{ Income (won/month) } \\
\hline Less than 3 million & 98 & $1.47 \pm 0.19$ & & $0.54 \pm 0.05$ & \\
\hline 3 million or more & 300 & $1.55 \pm 0.15$ & 0.38 & $0.51 \pm 0.05$ & 0.38 \\
\hline Missing & 36 & $1.74 \pm 0.09$ & & $0.53 \pm 0.06$ & \\
\hline \multicolumn{6}{|l|}{ Passive smoking } \\
\hline No & 286 & $1.53 \pm 0.16$ & & $0.53 \pm 0.06$ & \\
\hline Yes & 137 & $1.60 \pm 0.16$ & 0.48 & $0.47 \pm 0.05$ & 0.31 \\
\hline Missing & 11 & $1.51 \pm 0.10$ & & $0.55 \pm 0.05$ & \\
\hline \multicolumn{6}{|c|}{ The length of residence (years) } \\
\hline 1 or less & 46 & $1.50 \pm 0.14$ & & $0.54 \pm 0.05$ & \\
\hline $2-3$ & 257 & $1.48 \pm 0.17$ & & $0.52 \pm 0.05$ & \\
\hline 4 or more & 120 & $1.70 \pm 0.14$ & 0.06 & $0.48 \pm 0.05$ & 0.88 \\
\hline Missing & 11 & $1.81 \pm 0.01$ & & $0.53 \pm 0.06$ & \\
\hline
\end{tabular}

GM, geometric mean

GSD, geometric standard deviation

where $\mathrm{Y}_{\mathrm{i}}$ is the level of blood lead or urinary cadmium. Variables such as gender, income, passive smoking, and the length of residence were included as dummy variables. All analyses were conducted with SAS software version 9.2.

\subsection{Calculation of Distance between Residence and Industrial Complex}

We used address information that were collected by the questionnaire and the location of SK industrial complex (600, Hwangseong-dong, Nam-gu, Ulsan, Korea) that is one of representative industrial complex in Ulsan. We calculated distance by using a Geographic Information System (ArcGIS version 10.0).

\section{RESULTS}

Table 1 summarizes the descriptive statistics of blood lead and urinary cadmium levels by gender, age, income, passive smoking, and the length of residence. The geometric mean lead level value was $1.55 \mu \mathrm{g} / \mathrm{dL}$, and the geometric mean cadmium level was $0.51 \mu \mathrm{g} / \mathrm{g}$ creatinine. Lead levels in boys were higher than in girls, while cadmium levels in boys were lower than in girls. In the case of cadmium, the difference between boys and girls was significant. When lead and cadmium levels were evaluated by age, both differed signi- ficantly, but they did not show definite trends. Income and passive smoking were not related to lead and cadmium levels. Cadmium levels showed a decreasing trend with increasing the length of residence but not significant.

In simple regression analyses of lead levels, distance and age were identified as significantly related to lead levels. Lead levels were higher as distance and age increased. Distance was significantly related to lead levels after adjusting for gender, age, income, passive smoking, and the length of residence (see Table 2).

In case of cadmium levels, distance, gender, and age were related significantly. Contrary to the results of lead levels, cadmium levels were lower as distance and age increased. Cadmium levels in girls were significantly higher than those in boys. In the multiple logistic regression models, after controlling for gender, age, income, passive smoking, and the length of residence, distance was significantly associated with cadmium levels (see Table 3 ).

\section{DISCUSSION}

In this study, we investigated 434 subjects (boys: 206, girls: 228) 7-13 years-of-age, living in Ulsan. We conducted questionnaire surveys and analyzed blood lead levels and urinary cadmium levels. Statistical analyses 
Table 2. Association of blood lead levels with variables based on regression analyses.

\begin{tabular}{|c|c|c|c|c|c|c|c|}
\hline \multirow{2}{*}{ Variables } & \multirow{2}{*}{$\mathrm{N}$} & \multicolumn{3}{|c|}{ Unadjusted } & \multicolumn{3}{|c|}{ Adjusted } \\
\hline & & $\beta$ & SE & $\mathrm{p}$-value & $\beta$ & SE & $\mathrm{p}$-value \\
\hline Distance & 434 & 0.03 & 0.01 & $<0.00$ & 0.02 & 0.01 & 0.00 \\
\hline \multicolumn{8}{|l|}{ Gender } \\
\hline Boys & 206 & reference & & & reference & & \\
\hline Girls & 228 & -0.05 & 0.07 & 0.45 & -0.07 & 0.07 & 0.40 \\
\hline Age & 434 & 0.16 & 0.05 & 0.00 & 0.14 & 0.05 & 0.01 \\
\hline \multicolumn{8}{|l|}{ Income (won/month) } \\
\hline Less than 3 million & 98 & reference & & & reference & & \\
\hline 3 million or more & 300 & 0.08 & 0.09 & 0.38 & 0.11 & 0.09 & 0.20 \\
\hline \multicolumn{8}{|l|}{ Passive smoking } \\
\hline No & 286 & reference & & & reference & & \\
\hline Yes & 137 & 0.05 & 0.08 & 0.50 & -0.02 & 0.08 & 0.77 \\
\hline \multicolumn{8}{|c|}{ The length of residence (years) } \\
\hline 1 or less & 46 & reference & & & reference & & \\
\hline $2-3$ & 257 & 0.04 & 0.12 & 0.77 & 0.03 & 0.12 & 0.79 \\
\hline 4 or more & 120 & 0.22 & 0.13 & 0.09 & 0.30 & 0.13 & 0.02 \\
\hline
\end{tabular}

SE, standard error

Table 3. Association of urinary cadmium levels with variables based on regression analyses.

\begin{tabular}{|c|c|c|c|c|c|c|c|}
\hline \multirow{2}{*}{ Variables } & \multirow{2}{*}{$\mathrm{N}$} & \multicolumn{3}{|c|}{ Unadjusted } & \multicolumn{3}{|c|}{ Adjusted } \\
\hline & & $\beta$ & SE & $\mathrm{p}$-value & $\beta$ & SE & $\mathrm{p}$-value \\
\hline Distance & 434 & -0.05 & 0.00 & $<0.00$ & -0.05 & 0.01 & $<0.00$ \\
\hline \multicolumn{8}{|l|}{ Gender } \\
\hline Boys & 206 & reference & & & reference & & \\
\hline Girls & 228 & 0.20 & 0.05 & 0.00 & 0.16 & 0.05 & 0.00 \\
\hline Age & 434 & -0.09 & 0.02 & 0.01 & 0.05 & 0.03 & 0.17 \\
\hline \multicolumn{8}{|l|}{ Income (won/month) } \\
\hline Less than 3 million & 98 & reference & & & reference & & \\
\hline 3 million or more & 300 & -0.06 & 0.07 & 0.38 & -0.04 & 0.06 & 0.51 \\
\hline \multicolumn{8}{|l|}{ Passive smoking } \\
\hline No & 286 & reference & & & reference & & \\
\hline Yes & 137 & -0.06 & 0.06 & 0.31 & 0.03 & 0.05 & 0.58 \\
\hline \multicolumn{8}{|c|}{ The length of residence (years) } \\
\hline 1 or less & 46 & reference & & & reference & & \\
\hline $2-3$ & 257 & -0.04 & 0.09 & 0.69 & 0.00 & 0.08 & 0.97 \\
\hline 4 or more & 120 & -0.05 & 0.10 & 0.61 & -0.03 & 0.09 & 0.71 \\
\hline
\end{tabular}

SE, standard error

were performed to assess the relationship between biomarkers collected from the children and distance between residence and industrial complex. The geometric mean lead level value was $1.55 \mu \mathrm{g} / \mathrm{dL}$ (boys: 1.59 , girls: 1.51 ), and the geometric mean cadmium level was 0.51 $\mu \mathrm{g} / \mathrm{g}$ creatinine (boys: 0.58 , girls: 0.45 ). According to multiple regression analysis, both lead and cadmium levels were significantly associated with distance. But lead levels increased and cadmium levels decreased as distance increased.

The mean lead level values from this study were lower than the results of most other studies, but cadmium levels were higher than those of other studies (see Table 4). Compared to the major cities of Korea, the mean values of lead in the air in Ulsan were low. The cadmium levels in the air decreased recently but were the highest in the major cities in 1993-2001 (National Istitute of Environmental Research, 2010).

Children are more sensitive to heavy metal exposure than adults for several reasons. Their exposure is increased by universal hand-to-mouth activity, their gut absorbs lead more readily than an adult's, and the developing central nervous system(CNS) is more vulnerable to toxicants than the mature CNS (Needleman, 2004). Cadmium is excreted very slowly and accumulates in the body, mainly in the kidneys. This process begins at a young age so current exposure will be a burden in coming years (Schoeters et al., 2006). 
Table 4. Study results of blood lead levels and urinary cadmium levels in children.

\begin{tabular}{|c|c|c|c|c|c|c|}
\hline & Population group & $\mathrm{N}$ & & Total & Boys & Girls \\
\hline \multirow{10}{*}{$\begin{array}{l}\text { Blood lead levels } \\
(\mu \mathrm{g} / \mathrm{dL})\end{array}$} & \multirow[t]{2}{*}{ Children living in Ulsan in Korea age $7-13$ years $^{\mathrm{a}}$} & \multirow[t]{2}{*}{695} & $\mathrm{AM}$ & 1.66 & 1.71 & 1.61 \\
\hline & & & GM & 1.49 & 1.55 & 1.43 \\
\hline & \multirow[t]{2}{*}{ US children age $1-5$ years $^{\mathrm{b}}$} & \multirow[t]{2}{*}{2532} & AM & - & - & - \\
\hline & & & GM & 1.9 & 1.9 & 1.9 \\
\hline & \multirow{2}{*}{ German children age 8-10 years living in an industrial area ${ }^{c}$} & \multirow[t]{2}{*}{245} & AM & 2.68 & - & - \\
\hline & & & GM & 2.50 & - & - \\
\hline & \multirow[t]{2}{*}{ Mexican-American children age 1-17 years ${ }^{\mathrm{d}}$} & \multirow[t]{2}{*}{3325} & $\mathrm{AM}$ & 3.47 & 3.78 & 3.15 \\
\hline & & & GM & - & - & - \\
\hline & \multirow[t]{2}{*}{ German children age $3-14$ years $^{\mathrm{e}}$} & \multirow[t]{2}{*}{1560} & AM & 1.82 & 1.94 & 1.69 \\
\hline & & & GM & 1.63 & 1.75 & 1.51 \\
\hline \multirow{9}{*}{$\begin{array}{l}\text { Urinary cadmium } \\
\text { levels } \\
\text { ( } \mu \mathrm{g} / \mathrm{g} \text { creatinine) }\end{array}$} & \multirow[t]{2}{*}{ Children living in Ulsan in Korea age 7-13 years ${ }^{\mathrm{a}}$} & \multirow[t]{2}{*}{695} & AM & 0.72 & 0.63 & 0.81 \\
\hline & & & GM & 0.54 & 0.49 & 0.59 \\
\hline & \multirow[t]{2}{*}{ US children age $6-12$ years ${ }^{\mathrm{f}}$} & \multirow[t]{2}{*}{776} & $\mathrm{AM}$ & - & - & - \\
\hline & & & GM & 0.09 & - & - \\
\hline & \multirow[t]{2}{*}{ Thailand children age $9-15$ years $^{\mathrm{g}}$} & \multirow[t]{2}{*}{849} & $\mathrm{AM}$ & 0.127 & 0.125 & 0.129 \\
\hline & & & GM & - & - & - \\
\hline & US children age $6-11$ years ${ }^{\mathrm{h}}$ & 3053 & AM & - & - & - \\
\hline & \multirow{2}{*}{ German children age $6-14$ years $^{\mathrm{i}}$} & \multirow{2}{*}{732} & AM & $\begin{array}{l}0.100 \\
-\end{array}$ & - & - \\
\hline & & & GM & 0.087 & 0.078 & 0.098 \\
\hline
\end{tabular}

\author{
$\mathrm{AM}$, arithmetic mean \\ GM, geometric mean \\ ${ }^{\text {athis study results }}$ \\ ${ }^{\mathrm{b} J o n e s}$ et al., 2009. \\ 'Wilhelm et al., 2002. \\ ${ }^{\mathrm{d}}$ Moralez et al., 2005. \\ ${ }^{\text {e} K o l o s s a-G e h r i n g ~ e t ~ a l ., ~} 2007$. \\ ${ }^{\mathrm{f}}$ Richter et al., 2009. \\ ${ }^{\mathrm{g}}$ Chaiwong et al., 2009. \\ hPaschal et al., 2000. \\ ${ }^{i}$ Hoffmann et al., 2000; Units are $\mu \mathrm{g} / \mathrm{L}$ (Creatinine was unadjusted).
}

Many studies focusing on children and heavy metals have been conducted. Lead was mainly investigated in regards to behavior (Mendelsohn et al., 1998) and intellectual impairment (Jusko et al., 2008; Lanphear et al., 2005; Canfield et al., 2003). Compared to studies of lead, research on cadmium in children is lacking (Schoeters et al., 2006).

In our results, lead levels in girls were lower than those in boys and cadmium levels in girls were higher than those in boys. In humans, the absorption of cadmium in low body iron stores was higher than that in bodies with normal stores. Because of low iron stores in women, absorption of cadmium and urinary cadmium levels in women were higher than those in men (Nordberg, 2007; Marie et al., 2006). This result is in agreement with other studies (Kolossa-Gehring et al., 2007; Moralez et al., 2005; Demoliou et al., 2004; Hoffmann et al., 2000; Paschal et al., 2000; Cambra et al., 1995).

Socioeconomic status is reportedly an important predictor related to lead and cadmium levels. People of high socioeconomic status reportedly had lower levels compared to those of low socioeconomic status (Menke et al., 2009; Richter et al., 2009; Kolossa-Gehring et al., 2007; Moralez et al., 2005; Bernard et al., 2003). In this study however, lead levels showed an increasing trend with rising income in contrast to previous studies, but it was not statistically significant. The relationship between cadmium levels and income was also not significant, but showed a decreasing trend with increasing income which is in agreement with previous studies.

Ulsan, where the participants lived, is a representative industrial city in Korea. There have been various industrial complexes (automobile, vessel, and petrochemical) in the city since the 1960 s when Korea initiated economic development. In the 1970s-1980s, environmental problems occurred and health issues emerged as well. Researchers still take interest in Ulsan as a study area even though the quality of the environment has been better due to citizens and government efforts to improve conditions since the 1990s (the Ulsan History Compilation Committee, 2002).

There are various studies reporting differences in lead and cadmium levels among areas, mainly near particular points including industrial sites (Sanna, 2003; 
Alonso et al., 2001), abandoned metal recovery plants (Kosatsky et al., 1994), lead-reclamation plants (Levallois et al., 1991), or e-waste recycling towns (Zheng et al., 2008). According to these studies, blood lead and urinary cadmium levels in children who live near industrial sites were higher than those who live in comparison area.

In this study, we found evidence in support of the hypothesis that where one lives is related to exposure to pollutants such as lead and cadmium. We found that urinary cadmium levels were significantly decreased as distance between residence and industrial complex increased after adjusting for age, gender, income, passive smoking and the length of residence. This result is opposite of that for lead levels. Sources of lead vary so that people are exposed anywhere, regardless of where they live, while exposure to cadmium is specific so that urinary cadmium levels may differ according to area of residence. Lee et al. (2001) showed the study results that difference in blood lead levels between children who had lived near industrial area in Ulsan and children who had lived in suburban districts decreased over the years. It might be result from an increase of exposure source for lead except industrial sites.

There are several limitations of this study. First, we selected some elementary schools and recruited students to participate in the study. The schools were chosen so that areas of residence did not spread evenly but might be congregated in some spots in Ulsan. Therefore, bio-marker levels of study subjects may not be representative of their areas.

Second, the location of industrial complex was considered as a dot although there are various industrial complex like a petrochemical plant, shipbuilding yard, etc. in Ulsan. The dot was located near seaside so that it is possible that distance was overcalculated and the relationship was underestimated. But the relative distance might not change because distance was calculated on same basis to all of participants. So that would not affect its validity.

Third, since passive smoking is related to lead and cadmium levels (Arora et al., 2008; Willers et al., 2005) we researched the frequency of passive smoking but there were many missing values $(24.7 \%)$. Parents' occupations are also reportedly an important factor associated with lead and cadmium levels (Zheng et al., 2008; Bernard et al., 2003; Cambra et al., 1995; Willers et al., 1988), but we did not include this variable in our investigation; therefore, it is possible that our results remain confounded by unmeasured covariates despite the fact that we controlled for other important factors.

Lastly, variables accounting for food ingestion were not considered in this study though food ingestion is a major source of lead and cadmium exposure to human. Because food ingestion is not associated with the distances between residence and industrial complex, exclusion of food ingestion might not undermine the validity of this study.

\section{CONCLUSIONS}

We investigated the relationship between blood lead and urinary cadmium levels and the proximity to industrial complex for children aged 7-13. In this study results, blood lead levels were increased while urinary cadmium levels were decreased as distance from industrial complex was increased. Our observations support the hypothesis that urinary cadmium levels in children are related to their proximity to an industrial complex. There are lots of exposure source of lead and cadmium besides industrial complex so further studies considering various exposure sources are required.

\section{ACKNOWLEDGEMENT}

The study was financially supported by National Institute of Environmental Research, Korea.

\section{REFERENCES}

Alonso, E., Camera, K., Martinez, T. (2001) Lead and cadmium exposure from contaminated soil among residents of a farm area near an industrial site. Archives of Environmental Health 56(3), 278-282.

Armstrong, B.K., White, E., Saracci, R. (1992) Principles of Exposure Measurement in Epidemiology, Oxford University Press Inc., New York, pp. 22-48.

Arora, M., Weuve, J., Schwartz, J., Wright, R.O. (2008) Association of environmental cadmium exposure with pediatric dental caries. Environmental Health Perspectives 116(6), 821-825.

Bernard, S.M., McGeehin, M.A. (2003) Prevalence of blood lead levels $>$ or $=5$ microg $/ \mathrm{dL}$ among US children 1 to 5 years of age and socioeconomic and demographic factors associated with blood of lead levels 5 to $10 \mathrm{microg} / \mathrm{dL}$, Third National Health and Nutrition Examination Survey, 1988-1994. Pediatrics 112(6 Pt1), 1308-1313.

Brasche, S., Bischof, W. (2005) Daily time spent indoors in German homes - Baseline data for the assessment of indoor exposure of German occupants. International Journal of Hygiene and Environmental Health, 208, 247-253.

Cambra, K., Alonso, E. (1995) Blood lead levels in 2- to 
3-year-old children in the Greater Bilbao Area (Basque Country, Spain): relation to dust and water lead levels. Archives of Environmental Health 50(5), 362-366.

Canfield, R.L., Henderson, C.R., Jr., Cory-Slechta, D.A., Cox, C., Jusko, T.A., Lanphear, B.P. (2003) Intellectual impairment in children with blood lead concentrations below 10 microg per deciliter. New England Journal of Medicine 348(16), 1517-1526.

Chaiwong, S., Sthiannopkao, S., Kim, K.W., Chuenchoojit, S., Poopatpiboon, K., Poodendean, C., Supanpaiboon, W. (2009) Urinary cadmium level in children between nine to fifteen years old in three Sub-districts of Tak Province in Thailand. Physics Procedia 2(1), 121125.

Demoliou, C.D., Charalambous, A. (2004) Blood lead levels in preprimary school-age children in Nicosia, Cyprus, and their relationship with leaded soil dust exposure. Archives of Environmental Health 59(9), 455461.

Hoffmann, K., Becker, K., Friedrich, C., Helm, D., Krause, C., Seifert, B. (2000) The German Environmental Survey 1990/1992 (GerES II): cadmium in blood, urine and hair of adults and children. Journal of Exposure Analysis and Environmental Epidemiology 10(2), 126135.

Jenkins, P.L., Phillips, T.J., Mulberg, E.J., Hui, S.P. (1992) Activity patterns of Californians: use of and proximity to indoor pollutant sources. Atmospheric Environment 26A(12), 2141-2148.

Jones, R.L., Homa, D.M., Meyer, P.A., Brody, D.J., Caldwell, K.L., Pirkle, J.L., Brown, M.J. (2009) Trends in blood lead levels and blood lead testing among US children aged 1 to 5 years, 1988-2004. Pediatrics 123(3), e376-385.

Jusko, T.A., Henderson, C.R., Lanphear, B.P., Cory-Slechta, D.A., Parsons, P.J., Canfield, R.L. (2008) Blood lead concentrations $<10 \mathrm{microg} / \mathrm{dL}$ and child intelligence at 6 years of age. Environmental Health Perspectives 116(2), 243-248.

Klaassen, C.D., Watkins, J.B. (2003) Casarett \& Doull's essentials of toxicology, McGraw-Hill, New York.

Kolossa-Gehring, M., Becker, K., Conrad, A., Ludecke, A., Riedel, S., Seiwert, M., Schulz, C., Szewzyk, R. (2007) German Environmental Survey for Children (GerES IV)--first results. International Journal of Hygiene Environmental Health 210(5), 535-540.

Kosatsky, T., Boivin, M.C. (1994) Blood lead levels in children living near abandoned metal-recovery plants. Canadian Journal of Public Health 85(3), 158-162.

Lanphear, B.P., Hornung, R., Khoury, J., Yolton, K., Baghurst, P., Bellinger, D.C., Canfield, R.L., Dietrich, K.N., Bornschein, R., Greene, T., Rothenberg, S.J., Needleman, H.L., Schnaas, L., Wasserman, G., Graziano, J., Roberts, R. (2005) Low-level environmental lead exposure and children's intellectual function: an international pooled analysis. Environmental Health Perspectives 113(7), 894-899.

Lee, C.R., Yoo, C.I., Lee, J.H., Lee, H., Kim, Y. (2001)
Trend of the changes in the level of blood lead, urinary arsenic and urinary cadmium of children in Ulsan: 3year follow-up study. Korean Journal of Preventive Medicine 34(2), 166-174.

Levallois, P., Lavoie, M., Goulet, L., Nantel, A.J., Gingras, S. (1991) Blood lead levels in children and pregnant women living near a lead-reclamation plant. Canadian Medical Association Journal 144(7), 877-885.

Marie, V., Agneta, A., Carola, L., Sandra, C., Marika, B. (2006) Gender differences in the disposition and toxicity of matals. Environmental Research 104, 85-95.

Mendelsohn, A.L., Dreyer, B.P., Fierman, A.H., Rosen, C.M., Legano, L.A., Kruger, H.A., Lim, S.W., Courtlandt, C.D. (1998) Low-level lead exposure and behavior in early childhood. Pediatrics 101(3), E10.

Menke, A., Muntner, P., Silbergeld, E.K., Platz, E.A., Guallar, E. (2009) Cadmium levels in urine and mortality among U.S. adults. Environmental Health Perspectives 117(2), 190-196.

Moralez, L.S., Gutierrez, P., Escarce, J.J. (2005) Demographic and socioeconomic factors associated with blood lead levels among Mexican-American children and adolescents in the United States. Public Health Reports 120(4), 448-454.

National Istitute of Environmental Research (2010) Annual Report of Ambient Air Quality in Korea, 2009.

National Institute of Environmental Research (2008) Korean National Human Exposure and Bio-monitoring Examination, 3rd.

Needleman, H. (2004) Lead poisoning. Annual Review of Medicine 55, 209-222.

Nordberg, G. (2007). Handbook on the Toxicology of Metals, Academic Pr., Burlington.

Paschal, D.C., Burt, V., Caudill, S.P., Gunter, E.W., Pirkle, J.L., Sampson, E.J., Miller, D.T., Jackson, R.J. (2000) Exposure of the U.S. population aged 6 years and older to cadmium: 1988-1994. Archives of Environmental Contamination and Toxicology 38(3), 377383.

Richter, P.A., Bishop, E.E., Wang, J., Swahn, M.H. (2009) Tobacco smoke exposure and levels of urinary metals in the U.S. youth and adult population: the National Health and Nutrition Examination Survey (NHANES) 1999-2004. International Journal of Environmental Research and Public Health 6(7), 1930-1946.

Sanna, E., Liguori, A., Palmas, L., Soro, M.R., Floris, G. (2003) Blood and hair lead levels in boys and girls living in two Sardinian towns at different risks of lead pollution. Ecotoxicology and Environmental Safety 55(3), 293-299.

Schoeters, G., den Hond, E.D., Zuurbier, M., Naginiene, R., van den Hazel, P., Stilianakis, N., Ronchetti, R., Koppe, J.G. (2006) Cadmium and children: Exposure and health effects. Acta Paediatrica 95, 50-54.

The Ulsan History Compilation Committee (2002) The History of Ulsan, Hansung publishing company, Ulsan. Wilhelm, M., Pesch, A., Rostek, U., Begerow, J., Schmitz, N., Idel, H., Ranft, U. (2002) Concentrations of lead in 
blood, hair and saliva of German children living in three different areas of traffic density. Science of the Total Environment 297(1-3), 109-118.

Willers, S., Gerhardsson, L., Lundh, T. (2005) Environmental tobacco smoke (ETS) exposure in children with asthma-relation between lead and cadmium, and cotinine concentrations in urine. Respiratory Medicine 99 (12), 1521-1527.

Willers, S., Schutz, A., Attewell, R., Skerfving, S. (1988) Relation between lead and cadmium in blood and the involuntary smoking of children. Scandinavian Journal of Work, Environment \& Health 14(6), 385-389.

Zheng, L., Wu, K., Li, Y., Qi, Z., Han, D., Zhang, B. (2008) Blood lead and cadmium levels and relevant factors among children from an e-waste recycling town in China. Environmental Research 108(1), 15-20.

(Received 23 July 2012, revised 27 February 2013, accepted 3 March 2013) 